\title{
The efficacy of moxifloxacin-based triple therapy in treatment of Helicobacter pylori infection: a systematic review and meta-analysis of randomized clinical trials
}

\author{
G. Zhang, J. Zou, F. Liu, Z. Bao, F. Dong, Y. Huang and S. Yin
}

Department of Gastroenterology, Huadong Hospital, Fudan University, Shanghai, China

\begin{abstract}
Recent evidence shows that moxifloxacin could exert an antimicrobial effect against Helicobacter pylori in both in vitro and in vivo models. To systematically evaluate whether moxifloxacin-containing triple therapy could improve eradication rates and reduce side effects in first-line or second-line anti- $H$. pylori treatment, eligible articles were identified by searches of electronic databases. We included all randomized trials comparing moxifloxacin-based triple therapy with standard triple or quadruple therapy during $H$. pylori eradication treatment. Statistical analysis was performed with Review Manager 5.0.10. Subanalysis/ sensitivity analysis was also performed. We identified seven randomized trials $(n=1263)$. Pooled $H$. pylori eradication rates were $79.03 \%$ (95\% Cl: $75.73-82.07)$ and $68.33 \%(95 \% \mathrm{Cl}: 64.44-72.04)$ for patients with moxifloxacin-based triple therapy or with standard triple or quadruple therapy, respectively (intention-to-treat analysis). The odds ratio (OR) was 1.82 (95\% Cl: $1.17-$ $2.81)$, the occurrence of total side effects was $15.23 \%(95 \% \mathrm{Cl}: 12.58-18.20)$ and $27.17 \%(95 \% \mathrm{Cl}: 23.64-30.92)$ for groups with or without moxifloxacin, and the summary OR was $0.45(95 \% \mathrm{Cl}: 0.26-0.77)$. In subgroup analyses, we noted that the secondline eradication rate in the moxifloxacin group was significantly higher than that in the quadruple therapy group (73.33 vs $60.17 \%$, OR: $1.78,95 \% \mathrm{Cl}: 1.16-2.73, \mathrm{P}<0.001)$. However, there was no difference in first-line eradication treatment. Findings from this meta-analysis suggest that moxifloxacin-based triple therapy is more effective and better tolerated than standard triple or quadruple therapy. Therefore, a moxifloxacin-based triple regimen should be used in the second-line treatment of $H$. pylori infection.
\end{abstract}

Key words: Moxifloxacin; Helicobacter pylori; Eradication rate; Side effects; Meta-analysis

\section{Introduction}

Helicobacter pylori infection is a common and significant public health problem; it can be found in $70-90 \%$ of the population in developing countries and in $25-50 \%$ in developed countries (1). Eradication of $H$. pylori is the recommended treatment for gastric and duodenal ulcers, gastric cancer, atrophic gastritis, mucosa-associated lymphoma tissue lymphoma, and other $H$. pylori-related complications (2-4). According to the Maastricht consensus, the first-line therapy for $H$. pylori eradication is a combination of proton pump inhibitors (PPI) or ranitidine bismuth citrate and clarithromycin plus either amoxicillin or metronidazole (5). In first-line therapies, eradication rates using combinations of $\mathrm{PPI}$-based triple therapies range from 75 to $98 \%$, with most of them near $80 \%(6-8)$. This signifies that up to $20 \%$ of patients are expected to be treatment failures, a value which, as already observed
(9), could be even higher in areas with a high prevalence of resistant $H$. pylori strains. The recommended secondline therapy is a quadruple regimen composed of tetracycline, metronidazole, bismuth salts, and a PPI; however, a pooled analysis of 40 trials demonstrated an average eradication rate of $76 \%$ for quadruple therapy when used as second-line therapy (10). Furthermore, this regimen requires the administration of four drugs with a complex scheme, and is associated with a relatively high incidence of adverse effects (11).

Moxifloxacin is a second-generation fluoroquinolone with an antibacterial spectrum that includes all major upper and lower respiratory tract pathogens, including beta-lactamase and macrolide-resistant pneumococci, and is currently widely used to treat infections of the respiratory tract, skin, and skin structures (12). Recently,

Correspondence: Z. Bao, Department of Gastroenterology, Huadong Hospital, Fudan University, 221 Yan an Xi Road, Shanghai 200040, China. Fax: +86-21-321-40503. E-mail: xinyi8681@sina.com 
several reports have demonstrated that moxifloxacinbased regimens provide excellent first-line therapies and rescue regimens for $H$. pylori eradication (13-16). Two meta-analyses showed the advantages of moxifloxacincontaining triple therapy for first-line and second-line treatment of $H$. pylori infection; however, some trials included in the two meta-analyses were of low quality, and the trials using moxifloxacin-containing triple therapy were not thoroughly analyzed $(17,18)$.

Therefore, we systematically reviewed the $H$. pylori eradication efficacy and tolerance of moxifloxacin-based triple therapy as first-line and second-line treatments of $H$. pylori infection. By summarizing the data from highquality randomized controlled trials, meta-analysis provides greater statistical power and a more precise estimate of eradication rates with moxifloxacin-based triple therapy in patients with $H$. pylori infection. This analysis also provides a more precise comparison of the frequency of side effects associated with the regimens. As a first-line therapy, we compared moxifloxacin-based regimens with standard triple therapy, while as a second-line therapy, we compared moxifloxacin-based regimens with quadruple therapy.

\section{Material and Methods}

\section{Selection of studies}

Studies evaluating moxifloxacin-based triple therapy for the eradication of $H$. pylori were considered. For the meta-analysis, the selection criteria were as follows: i) articles had to report comparative randomized-controlled trials; ii) they had to include at least two treatment arms consisting of triple therapy (a PPI and two antibiotics) or quadruple therapy (i.e., PPI, bismuth, and two antibiotics or ranitidine bismuth citrate plus these same antibiotics) and a moxifloxacin-involved regimen; iii) the study population consisted of subjects first treated and retreated; iv) the data of successful eradication and/or side effects in $H$. pylori eradication were available.

\section{Search strategy for identification of studies}

Trials were identified by searching the Cochrane Controlled Trials Register (Issue 1, 2012), PubMed (1966 to March 2012), Embase (1980 to March 2012), and the Science Citation Index (1945 to March 2012). A search strategy was constructed using a combination of the following words: Helicobacter pylori or $H$. pylori and moxifloxacin or avelox. Only articles published in English were included. Reference lists from the trials selected by electronic searching were manually searched to identify further relevant trials. We also conducted a manual search of abstracts from 1995 to 2012 (March) from the following congresses: International Workshop of the European Helicobacter Study Group, American Digestive Disease Week, and United European Gastroenterology Week. Abstracts of the articles selected in each of these multiple searches were reviewed, and those meeting the inclusion criteria were recorded. References of reviews on $\mathrm{H}$. pylori treatment with moxifloxacin and from the articles selected for the study were also examined for articles meeting the inclusion criteria. Authors of some identified trials were asked whether they knew of additional studies, including unpublished randomized ones. In the case of duplicate reports, or studies obviously reporting results from the same study population, only the latest published results were used.

\section{Data extraction}

Standardized data abstraction sheets were prepared. Data were extracted for study quality, dose and duration of moxifloxacin treatment, and anti- $H$. pylori regimens, as well as for the number of enrolled subjects, diagnostic methods of testing $H$. pylori infection before enrolling and after completing the study, and score systems for assessing side effects. Meanwhile, key outcomes data such as eradication rates, occurrence of diarrhea, nausea, taste disturbance, and abdominal pain were abstracted from all included studies. All articles were examined independently for eligibility by two reviewers. Disagreements were resolved by consulting a third reviewer. Quality was assessed using Jadad scoring based on three items: randomization, double blinding, and description of withdrawals/dropouts. We considered that trials were of low quality if their scores were less than 3.

\section{Data synthesis}

Data were entered into the Cochrane Collaboration Review Manager program RevMan 5.0.10 (released on May 16, 2008, The Nordic Cochrane Centre, The Cochrane Collaboration, Rigs Hospitalet, Denmark). The outcome measure examined was the odds ratio (OR) of improving $H$. pylori eradication rates and reducing side effects with moxifloxacin-based triple therapy vs standard triple or quadruple therapy. Categorical variables were compared with the chi-square test, and $\mathrm{P}<0.05$ was considered to be statistically significant. Eradication rates and side effects were analyzed based on a fixed-effects model using the methods of Mantel-Haenszel both by an intention-to-treat and by a per-protocol. Heterogeneity among the studies was assessed by the chi-square test. Statistical significance of heterogeneity was set at 0.10 . If the heterogeneity was significant, subanalysis was used. Where the heterogeneity was not obvious and $P>0.10$, we employed the fixed-effect model; otherwise, we used the random-effect model.

\section{Subanalysis/sensitivity analysis}

In the meta-analysis, subanalyses of $H$. pylori eradication efficacy were planned a priori depending on: i) the type of drugs co-prescribed with moxifloxacin (the combination with amoxicillin or metronidazole and a PPI is the most widely prescribed), ii) the country of the 
subjects, iii) the $H$. pylori eradication times, and iv) the quality of the studies (based on the quality score proposed by JADAD; see appropriate section). In the sensitivity analysis, we evaluated the influence of low quality studies by estimating the ORs in the absence of one or more studies (we used JADAD scores to assess the quality of studies; if the JADAD score of the study was below 3, we could tell that the study was of low quality). Finally, we used funnel plot asymmetry to detect any publication bias in the meta-analysis and Egger's regression test to measure funnel plot asymmetry. If the funnel plot was almost symmetrical, we could say that there was no obvious publication bias.

\section{Results}

\section{Description of the studies}

The bibliographical search yielded a total of 59 studies. Of these studies, 14 were excluded owing to publication type, (i.e., seven reviews, three comments, and four letters). We excluded another 19 articles (10 non-clinical trials and 9 unrelated articles) after examining the title and abstract, the remaining 26 potentially relevant articles were retrieved for more detailed assessment. From these 26 articles, we excluded another 11, because there was no control group. Eight study groups were also excluded because of comparisons of different courses, or containing moxifloxacin in two regimens, or the absence of an eligible control group. Finally, seven randomized controlled trails (RCTs) (13-16,19-21) met the inclusion criteria (Figure 1). The characteristics of the seven trials included in this meta-analysis are summarized in Table 1, including quality scores.

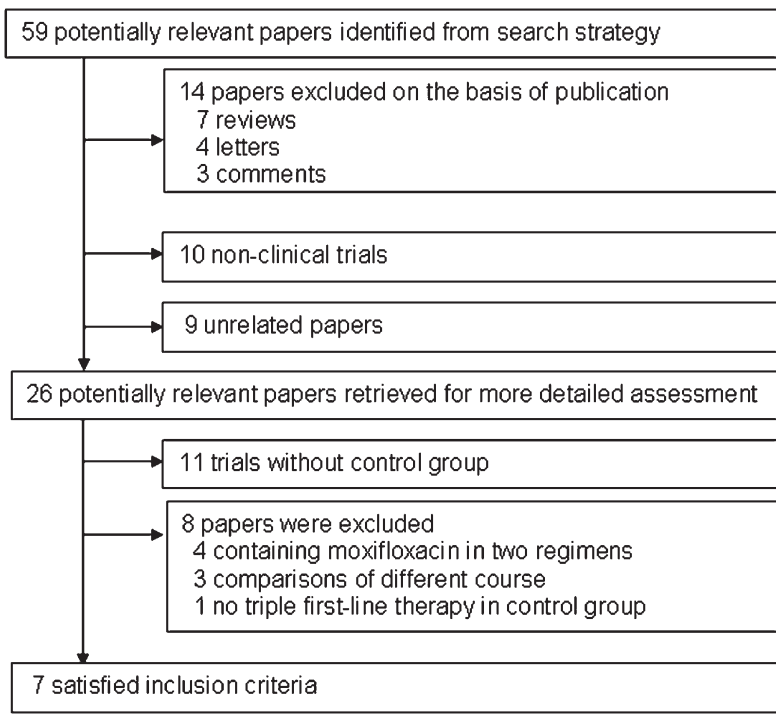

Figure 1. Flow diagram of search strategy and study selection.

\section{Eradication rates}

Seven studies that described $H$. pylori eradication rates were selected for the meta-analysis. Of these selected studies, five reported significantly improved eradication rates, and the remaining two studies had similar efficacies for $H$. pylori eradication. The pooled intention-to-treat data showed that 524 of 663 patients with moxifloxacin-based triple regimens $(79.03 \%$; $95 \% \mathrm{Cl}$ : 75.73-82.07) and 410 of 600 patients given regimens without moxifloxacin (68.33\%; 95\% Cl: 64.44-72.04) achieved eradication. The OR was $1.82(95 \% \mathrm{Cl}$ : $1.17-$ 2.81; Supplementary Figure S1). Overall, per-protocol eradication rates were $84.24 \%(95 \% \mathrm{Cl}$ : 81.14-87.02) and $75.79 \%(95 \% \mathrm{Cl}: 71.95-79.34)$ for moxifloxacin-based triple regimen and regimen without moxifloxacin, respectively (OR: $1.65 ; 95 \% \mathrm{Cl}$ : 0.95-2.86).

\section{Side effects}

Total side effects were initially included in the metaanalysis because data for occurrence of total side effects could be obtained from all the RCTs. Of these studies, three trials reported a significantly lower incidence of gastrointestinal side effects with moxifloxacin. Side effects in moxifloxacin-based regimens were less than in regimens without moxifloxacin: $15.23 \%(95 \% \mathrm{Cl}$ : 12.58-18.20) and $27.17 \%(95 \% \mathrm{Cl}: 23.64-30.92)$, respectively; the summary OR was $0.45(95 \% \mathrm{Cl}: 0.26-0.77)$ (Supplementary Figure S2).

\section{Subanalysis/sensitivity analysis}

Subanalyses for the meta-analysis were planned depending on choice of antibiotics, eradication times, and the country in which subjects were treated. We divided all eligible trials into moxifloxacin +amoxicillin $(\mathrm{M}+\mathrm{A})$ and moxifloxacin + metronidazole/tinidazole $(\mathrm{M}+\mathrm{Me} / \mathrm{T})$ subgroups, first treatment and rescue treatment subgroups, or Asia and Europe subgroups. For antibiotics subanalysis, the $\mathrm{M}+\mathrm{A}$ subgroup had no significant difference. However, the $M+M e / T$ subgroup had a significant difference, with summary ORs 1.50 (95\% Cl: 0.95-2.38) and 3.00 (95\% Cl: 1.84-4.89), respectively (Supplementary Figure 3 ). For time of eradication subanalysis, the first time subgroup had no difference and the rescue subgroup had significant difference, with summary ORs $1.80(95 \% \mathrm{Cl}: 0.71-4.55)$ and 1.78 (95\% Cl: 1.16-2.73), respectively (Supplementary Figure S4). For subanalysis by country of subjects, the Asia subgroup had no difference and the Europe subgroup had a significant difference, with summary ORs $1.27(95 \% \mathrm{Cl}$ : $0.71-2.29)$ and $2.71(95 \% \mathrm{Cl}: 1.87-3.93)$, respectively (Supplementary Figure 5).

In the sensitivity analysis, we first excluded two low quality studies, and eradication rates had no significant changes (OR: 2.11; 95\% Cl: 1.43-3.10); then we excluded the largest study, and eradication rates also had no significant changes (OR: 1.67; 95\% Cl: 1.02-2.73). 
Table 1. Characteristics of the 7 studies in this meta-analysis comparing $H$. pylori eradication efficacy with moxifloxacin-based triple therapy vs standard triple or quadruple therapy.

\begin{tabular}{|c|c|c|c|c|c|c|c|c|c|c|}
\hline $\begin{array}{l}\text { Reference/ } \\
\text { country }\end{array}$ & $\begin{array}{c}\text { Number } \\
\text { (moxifloxacin/ } \\
\text { control) }\end{array}$ & Diagnosis & $\begin{array}{l}\text { Diagnostic } \\
\text { methods }\end{array}$ & $\begin{array}{l}\text { Moxifloxacin } \\
\text { regimen } \\
\text { (duration) }\end{array}$ & $\begin{array}{c}\% \\
\text { Eradication } \\
\text { (No. of } \\
\text { patients) }\end{array}$ & $\begin{array}{l}\% \\
\text { Adverse } \\
\text { effects } \\
\text { (No. of } \\
\text { patients) }\end{array}$ & $\begin{array}{l}\text { Triple or } \\
\text { quadruple } \\
\text { regimen } \\
\text { (duration) }\end{array}$ & $\begin{array}{c}\% \\
\text { Eradication } \\
\text { (No. of } \\
\text { patients) }\end{array}$ & $\begin{array}{c}\% \\
\text { Adverse } \\
\text { effects } \\
\text { (No. of } \\
\text { patients) }\end{array}$ & $Q$ \\
\hline $\begin{array}{l}\text { Cheon (15) } \\
\text { Korea }\end{array}$ & $85(41 / 44)$ & $\begin{array}{l}\text { Peptic } \\
\text { ulcer, } \\
\text { gastric } \\
\text { adenoma } \\
\text { or cancer, } \\
\text { non-ulcer } \\
\text { dyspepsia }\end{array}$ & $\begin{array}{c}\text { UBT,RUT or } \\
\text { histology/UBT } \\
\text { (4 weeks later) }\end{array}$ & $\begin{array}{c}\text { E (20 mg bid }) \\
\text { A ( } 1 \mathrm{~g} \mathrm{bid}) \\
\text { M (400 mg qd }) \\
(7 \text { days })\end{array}$ & $\begin{array}{c}\text { ITT } 75.6 \\
(31 / 41) \\
\text { PP 83.8 } \\
(31 / 37)\end{array}$ & $\begin{array}{c}9.8 \\
(4 / 41)\end{array}$ & $\begin{array}{c}\text { E (20 mg bid) } \\
\text { B (300 mg qd) } \\
\text { Me (500 mg tid) } \\
\text { T (500 mg qd) } \\
\text { (14 days) }\end{array}$ & $\begin{array}{c}\text { ITT } 54.5 \\
(24 / 44) \\
\text { PP } 72.7 \\
(24 / 33)\end{array}$ & $\begin{array}{c}27.3 \\
(12 / 44)\end{array}$ & 2 \\
\hline $\begin{array}{l}\text { Kang (19) } \\
\text { Korea }\end{array}$ & $192(139 / 53)$ & $\begin{array}{l}\text { Peptic } \\
\text { ulcer, } \\
\text { dysplasia } \\
\text { or gastric } \\
\text { cancer } \\
\text { non-ulcer } \\
\text { dyspepsia }\end{array}$ & $\begin{array}{c}\text { UBT,RUT or } \\
\text { histology/UBT } \\
\text { (4 weeks later) }\end{array}$ & $\begin{array}{c}\text { E (20 mg bid }) \\
\text { A (1 g bid }) \\
\text { M (400 mg qd }) \\
\text { (10 days })\end{array}$ & $\begin{array}{c}\text { ITT } 71.9 \\
(100 / 139) \\
\text { PP 82.6 } \\
(100 / 121)\end{array}$ & $\begin{array}{c}12.2 \\
(17 / 139)\end{array}$ & $\begin{array}{c}\text { E (20 mg bid) } \\
\text { B (300 mg qd) } \\
\text { Me (500 mg tid) } \\
\text { T (500 mg qd) } \\
\text { (14 days) }\end{array}$ & $\begin{array}{c}\text { ITT } 71.7 \\
(38 / 53) \\
\text { PP } 90.5 \\
(38 / 42)\end{array}$ & $\begin{array}{c}39.6 \\
(21 / 53)\end{array}$ & 4 \\
\hline $\begin{array}{l}\text { Bago (16) } \\
\text { Croatia }\end{array}$ & $160(82 / 78)$ & $\begin{array}{l}\text { Non-ulcer } \\
\text { dyspepsia }\end{array}$ & $\begin{array}{c}\text { UBT/UBT } \\
\text { (6 weeks later) }\end{array}$ & $\begin{array}{c}\text { O (20 mg bid }) \\
\text { M (400 mg qd) } \\
\text { Me (500 mg tid }) \\
\quad(7 \text { days })\end{array}$ & $\begin{array}{c}\text { ITT } 73.2 \\
(60 / 82) \\
\text { PP 78.9 } \\
(60 / 76)\end{array}$ & $\begin{array}{c}14.6 \\
(12 / 82)\end{array}$ & $\begin{array}{c}\mathrm{O}(20 \mathrm{mg} \mathrm{bid}) \\
\mathrm{B}(120 \mathrm{mg} \mathrm{qd}) \\
\mathrm{Me}(500 \mathrm{mg} \text { tid }) \\
\mathrm{T}(500 \mathrm{mg} \text { qd }) \\
(7 \text { days })\end{array}$ & $\begin{array}{l}\text { ITT } 53.8 \\
(42 / 78) \\
\text { PP 64.6 } \\
(42 / 65)\end{array}$ & $\begin{array}{c}23.1 \\
(18 / 78)\end{array}$ & 3 \\
\hline $\begin{array}{l}\text { Zheng (20) } \\
\text { China }\end{array}$ & $109(53 / 56)$ & $\begin{array}{l}\text { Peptic } \\
\text { ulcer, } \\
\text { chronic } \\
\text { gastritis }\end{array}$ & $\begin{array}{c}\text { UBT/UBT } \\
\text { (4 weeks later) }\end{array}$ & $\begin{array}{c}\mathrm{R}(10 \mathrm{mg} \mathrm{bid}) \\
\mathrm{A}(1 \mathrm{~g} \mathrm{bid}) \\
\mathrm{M}(400 \mathrm{mg} \mathrm{qd}) \\
(7 \text { days })\end{array}$ & $\begin{array}{c}\text { ITT } 75.5 \\
(40 / 53) \\
\text { PP 83.3 } \\
(40 / 48)\end{array}$ & $\begin{array}{c}9.4 \\
(5 / 53)\end{array}$ & $\begin{array}{c}\mathrm{R}(10 \mathrm{mg} \text { bid }) \\
\mathrm{B}(150 \mathrm{mg} \text { tid }) \\
\mathrm{C}(500 \mathrm{mg} \text { bid }) \\
\operatorname{Me}(400 \mathrm{mg} \text { bid }) \\
(7 \text { days })\end{array}$ & $\begin{array}{c}\text { ITT } 62.5 \\
(35 / 56) \\
\text { PP } 71.4 \\
(35 / 49)\end{array}$ & $\begin{array}{c}16.1 \\
(9 / 56)\end{array}$ & 4 \\
\hline $\begin{array}{l}\text { Nista (13) } \\
\text { Italy }\end{array}$ & $320(160 / 160)$ & $\begin{array}{l}\text { Non-ulcer } \\
\text { dyspepsia }\end{array}$ & $\begin{array}{c}\text { histology + UBT/ } \\
\text { UBT ( } 6 \text { weeks } \\
\text { later) }\end{array}$ & $\begin{array}{c}\text { E (20 mg bid }) \\
\text { A (1 g bid }) \\
\text { T (500 mg bid }) \\
\text { M (400 mg qd }) \\
(7 \text { days })\end{array}$ & $\begin{array}{c}\text { ITT } 88.8 \\
(142 / 160) \\
\text { PP } 90.4 \\
(142 / 157)\end{array}$ & $\begin{array}{c}13.1 \\
(21 / 160)\end{array}$ & $\begin{array}{c}\text { E (20 mg bid }) \\
\text { A (1 g bid }) \\
\text { T (500 mg bid }) \\
\text { C (500 mg bid }) \\
\text { (7 days })\end{array}$ & $\begin{array}{c}\text { ITT } 73.8 \\
(118 / 160) \\
\text { PP } 78.7 \\
(118 / 150)\end{array}$ & $\begin{array}{c}34.4 \\
(55 / 160)\end{array}$ & 3 \\
\hline $\begin{array}{l}\text { Bago (14) } \\
\text { Croatia }\end{array}$ & $277(128 / 149)$ & $\begin{array}{l}\text { Non-ulcer } \\
\text { dyspepsia }\end{array}$ & $\begin{array}{c}\text { histology +RUT } \\
\text { or culture/ } \\
\text { histology + RUT } \\
\text { or culture (4-6 } \\
\text { weeks later) }\end{array}$ & $\begin{array}{c}\text { L (30 mg bid }) \\
\text { A ( } 1 \mathrm{~g} \mathrm{bid}) \\
\text { Me (400 mg } \\
\text { bid }) \\
\text { M (400 mg qd }) \\
\text { (7 days) }\end{array}$ & $\begin{array}{c}\text { ITT } 89.8 \\
(115 / 128) \\
\text { PP 93.5 } \\
(115 / 123)\end{array}$ & $\begin{array}{c}6.3 \\
(8 / 128)\end{array}$ & $\begin{array}{c}\mathrm{L}(30 \mathrm{mg} \mathrm{bid}) \\
\mathrm{A}(1 \mathrm{~g} \mathrm{bid}) \\
\mathrm{Me}(400 \mathrm{mg} \mathrm{bid}) \\
\mathrm{C}(500 \mathrm{mg} \text { bid }) \\
(7 \text { days })\end{array}$ & $\begin{array}{c}\text { ITT } 74.5 \\
(111 / 149) \\
\text { PP } 78.2 \\
(111 / 142)\end{array}$ & $\begin{array}{c}13.4 \\
(20 / 149)\end{array}$ & 5 \\
\hline $\begin{array}{l}\text { Kilic (21) } \\
\text { Turkey }\end{array}$ & $120(60 / 60)$ & $\begin{array}{l}\text { Non-ulcer } \\
\text { dyspepsia }\end{array}$ & $\begin{array}{l}\text { histology or } \\
\text { RUT/UBT( } 8 \\
\text { weeks later) }\end{array}$ & $\begin{array}{c}\text { RBC (400 mg } \\
\text { bid) } \\
\text { E (40 mg bid) } \\
\text { A ( } 1 \mathrm{~g} \mathrm{bid)} \\
\text { M (400 mg qd }) \\
\text { (14 days) }\end{array}$ & $\begin{array}{l}\text { ITT 60 } \\
(36 / 60) \\
\text { PP 60 } \\
(36 / 60)\end{array}$ & $\begin{array}{c}56.7 \\
(34 / 60)\end{array}$ & $\begin{array}{c}\text { RBC (400 mg } \\
\text { bid) } \\
\text { E (40 mg bid) } \\
\text { A ( } 1 \mathrm{~g} \mathrm{bid)} \\
\text { C (500 mg bid) } \\
\text { (14 days) }\end{array}$ & $\begin{array}{l}\text { ITT } 70 \\
(42 / 60) \\
\text { PP 70 } \\
(42 / 60)\end{array}$ & $\begin{array}{c}46.7 \\
(28 / 60)\end{array}$ & 2 \\
\hline
\end{tabular}

C: clarithromycin; A: amoxicillin; R: rabeprazole; T: tinidazole; O: omeprazole; L: lansoprazole; E: esomeprazole; RBC: ranitidine bismuth citrate; B: bismuth subcitrate; M: moxifloxacin; Me: metronidazole; UBT: ${ }^{13} \mathrm{C}$-urea breath test; RUT: rapid urease test; ITT: intention-to-treat analysis; PP: per-protocol analysis; Q: quality score; qd: one time a day; bid: two times a day; tid: three times a day.

\section{Publication bias}

We found the funnel plot had a slightly asymmetrical distribution (Figure 2), but Egger's regression test suggested no significant asymmetry of the funnel plot $(P=0.860)$, indicating no evidence of substantial publication bias.

\section{Discussion}

Optimizing $H$. pylori eradication therapy remains an ongoing challenge worldwide. Conventional first-line eradication therapies may fail in up to $30 \%$ of patients, leading to a significant increase in antimicrobial resistance (22), particularly against the key antibiotics clarithromycin and/or metronidazole $(23,24)$. A sequential treatment containing PPI plus amoxicillin for 5 days followed by an additional 5 days of a PPI, clarithromycin, and metronidazole/tinidazole is suggested as an alternative, although most available data were collected in Italy where the rates

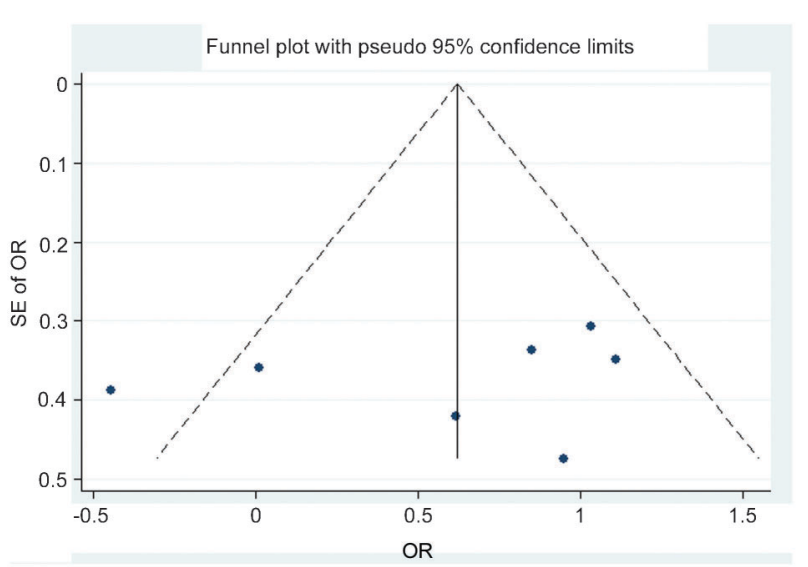

Figure 2. Funnel plot of included studies for eradication rates. 
for clarithromycin resistance are relatively high. Another option in first-line therapy is a quadruple therapy consisting of a PPI, amoxicillin, clarithromycin, and metronidazole $(5,25)$. The bismuth-based quadruple therapy containing a PPI or ranitidine, bismuth subsalicylate, metronidazole, and tetracycline is also partially recommended in first-line and second-line treatment for at least 10 days. $(5,25)$. Another possibility in second-line therapy is a combination of a quinolone and amoxicillin. For thirdline treatment, a combination of rifabutin and amoxicillin is suggested. In general, susceptibility testing is strongly recommended after second therapy failure (26).

Second-generation fluoroquinolones (levofloxacyn, moxifloxacin) have proved to have an antibacterial effect to $H$. pylori, especially in terms of safety and simplicity of dosing schedule. Moxifloxacin-containing triple therapies have achieved eradication rates up to $90 \%$ in first-line treatments and over $70 \%$ in second-line therapies. The results of our meta-analysis demonstrated higher $H$. pylori eradication rates with a moxifloxacin-based triple regimen than standard triple or quadruple regimens (79.03 vs $68.33 \%, \mathrm{P}<0.01)$, with OR 1.82 (95\%Cl: 1.17-2.81). We also found that, in first-line treatment, the eradication rate of a moxifloxacin-based triple regimen was not different from that of a standard triple regimen. But in second-line treatment, the eradication rate of a moxifloxacin-based triple regimen was significantly different from that of a quadruple regimen (73.33 vs $60.17 \%, \mathrm{P}<0.01)$. Regarding the choice of antibiotics for combination with moxifloxacin, we found that the $\mathrm{M}+\mathrm{Me} / \mathrm{T}$ subgroup had a higher cure rate $(P<0.01)$. It is possible that moxifloxacin and metronidazole or tinidazole exert a synergistic effect against $H$. pylori.

Based on a large body of published clinical trials and the result of our meta-analysis, a moxifloxacin-based PPI triple therapy is effective and safe, and shows better outcome parameters compared with the standard PPI first-line and second-line therapies. Compared with bismuth-based quadruple therapy, PPI triple regimens containing moxifloxacin are better tolerated and more effective. However, is this enough data to recommend a quinolone-based triple therapy in first-line therapy of H. pylori infection?

As mentioned earlier, primary quinolone resistance in $H$. pylori is reported to be relatively low in populations where quinolone consumption is low. Unfortunately, these values seem to have increased over the last years $(27,28)$. In other countries with high use of quinolones, a primary resistance of about $20 \%$ and higher has already been reported (29). In $H$. pylori, single point mutations in the gyrA gene, the quinolone resistance-determining region, cause resistance to this class of antibiotics (30). In Germany, the rate for quinolone-resistant $H$. pylori is about $10 \%$, rising to $17 \%$ after previous treatment failures (31). Similar values have recently been reported from other countries such as the United Kingdom (32), Italy (33), Japan (34), and Taiwan (28).
A recent study from Croatia including 150 patients with primary quinolone resistance $(6 \%)$ demonstrated a significant reduction of eradication success of moxifloxacincontaining PPI triple therapy in patients infected with quinolone-resistant $H$. pylori strains (66 vs 98\%) (35). Therefore, in populations with clarithromycin resistance greater than $15-20 \%$ and low quinolone resistance rates, a PPI triple therapy with moxifloxacin might be considered. For this strategy, an acceptable threshold of $10 \%$ for quinolone resistance is currently being discussed $(36,37)$. This seems to be a reasonable suggestion at present, since most of the studies in first-line, quinolone-based therapy have been performed in populations with quinolone resistance lower than $10 \%$. That again points out the importance of permanent surveillance of quinolone resistance within a given population in order to adapt recommendations appropriately. Patients who have been previously exposed to quinolones for other indications should not be treated with quinolone-containing eradication regimens.

Several methodological weaknesses may limit the validity and generalizability of this meta-analysis. First, there are no studies involving patients from North America or Africa. The studies included were conducted in Italy, Croatia, Turkey, Korea, and China. It is well established that antibiotic resistance profiles of $H$. pylori vary among different geographical regions for which a pharmacogenomic difference could exist (38). Such resistance profiles are likely to significantly impact the efficacy of moxifloxacinbased triple therapy, and thus may limit the generalizability of these results to African or American populations. Second, heterogeneity among trials can be another limitation of the meta-analysis; there were many factors causing heterogeneity, such as different regimens of drugs and duration. Third, ethnic differences might be another cause of heterogeneity, which may lead to different responses to $H$. pylori eradication therapy. Therefore, more high-quality, multicenter, randomized, controlled trials from other countries and regions are necessary.

In summary, moxifloxacin-based triple therapy is a safe and well-tolerated option in anti- $H$. pylori therapy. In second-line treatment, the combination of a PPI, moxifloxacin, and metronidazole or tinidazole is a valid option, especially in countries where bismuth salts are unavailable. In first-line therapy, a moxifloxacin-based triple therapy cannot generally be recommended. However, under specific circumstances, this combination might be considered as an individual first-line treatment option. Thus, in a population with low primary quinolone resistance and high primary clarithromycin resistance, a PPI triple therapy with moxifloxacin and metronidazole or tinidazole could be a valuable alternative.

\section{Supplementary Material}

Click here to view [pdf] 


\section{Acknowledgments}

Research supported by the Promotion of Appropriate
Technology and Application Projects for Municipal Hospitals, Shanghai Shenkang Hospital Development Center, China (SHDC12010213).

\section{References}

1. Go MF. Review article: natural history and epidemiology of Helicobacter pylori infection. Aliment Pharmacol Ther 2002; 16 (Suppl 1): 3-15, doi: 10.1046/j.1365-2036.2002.0160s1003.x.

2. Rauws EA, Tytgat GN. Cure of duodenal ulcer associated with eradication of Helicobacter pylori. Lancet 1990; 335: 1233-1235, doi: 10.1016/0140-6736(90)91301-P.

3. Brenes F, Ruiz B, Correa P, Hunter F, Rhamakrishnan T, Fontham $\mathrm{E}$, et al. Helicobacter pylori causes hyperproliferation of the gastric epithelium: pre- and post-eradication indices of proliferating cell nuclear antigen. Am J Gastroenterol 1993; 88: $1870-1875$.

4. Boot $\mathrm{H}$, de Jong $\mathrm{D}$, van Heerde $\mathrm{P}$, Taal $\mathrm{B}$. Role of Helicobacter pylori eradication in high-grade MALT lymphoma. Lancet 1995; 346: 448-449, doi: 10.1016/S01406736(95)92823-5.

5. Malfertheiner P, Megraud F, O'Morain C, Bazzoli F, El-Omar E, Graham D, et al. Current concepts in the management of Helicobacter pylori infection: the Maastricht III Consensus Report. Gut 2007; 56: 772-781, doi: 10.1136/ gut.2006.101634.

6. Perri F, Qasim A, Marras L, O'Morain C. Treatment of Helicobacter pylori infection. Helicobacter 2003; 8 (Suppl 1): 53-60, doi: 10.1046/j.1523-5378.2003.00162.x.

7. Kihira K, Satoh K, Saifuku K, Kawakami S, Fukazawa K, Ishino Y, et al. Rabeprazole, amoxycillin and low- or highdose clarithromycin for cure of Helicobacter pylori infection. Aliment Pharmacol Ther 2000; 14: 1083-1087, doi: 10.1046/ j.1365-2036.2000.00810.x.

8. Neville PM, Barrowclough S, Crocombe W, Axon AT, Wrangstadh M, Moayyedi P. Randomised study of the efficacy of omeprazole and clarithromycin with either amoxycillin or metronidazole in the eradication of Helicobacter pylori in screened primary care patients. Dig Liver Dis 2001; 33: 131134, doi: 10.1016/S1590-8658(01)80067-0.

9. Lee JM, Breslin NP, Hyde DK, Buckley MJ, O'Morain CA. Treatment options for Helicobacter pylori infection when proton pump inhibitor-based triple therapy fails in clinical practice. Aliment Pharmacol Ther 1999; 13: 489-496, doi: 10.1046/j.1365-2036.1999.00504.x

10. Hojo M, Miwa H, Nagahara A, Sato N. Pooled analysis on the efficacy of the second-line treatment regimens for Helicobacter pylori infection. Scand J Gastroenterol 2001; 36: 690-700, doi: 10.1080/003655201300191941.

11. Gisbert JP, Pajares JM. Review article: Helicobacter pylori "rescue" regimen when proton pump inhibitor-based triple therapies fail. Aliment Pharmacol Ther 2002; 16: 10471057, doi: 10.1046/j.1365-2036.2002.01276.x.

12. Keating GM, Scott LJ. Moxifloxacin: a review of its use in the management of bacterial infections. Drugs 2004; 64: 23472377, doi: 10.2165/00003495-200464200-00006.

13. Nista EC, Candelli M, Zocco MA, Cazzato IA, Cremonini F, Ojetti $\mathrm{V}$, et al. Moxifloxacin-based strategies for first-line treatment of Helicobacter pylori infection. Aliment Pharmacol Ther 2005; 21: 1241-1247, doi: 10.1111/j.1365-2036. 2005.02412.x.

14. Bago P, Vcev A, Tomic M, Rozankovic M, Marusic M, Bago $J$. High eradication rate of $H$. pylori with moxifloxacin-based treatment: a randomized controlled trial. Wien Klin Wochenschr 2007; 119: 372-378, doi: 10.1007/s00508007-0807-2.

15. Cheon JH, Kim N, Lee DH, Kim JM, Kim JS, Jung HC, et al. Efficacy of moxifloxacin-based triple therapy as second-line treatment for Helicobacter pylori infection. Helicobacter 2006; 11: 46-51, doi: 10.1111/j.0083-8703.2006.00371.x.

16. Bago J, Pevec B, Tomic M, Marusic M, Bakula V, Bago P Second-line treatment for Helicobacter pylori infection based on moxifloxacin triple therapy: a randomized controlled trial. Wien Klin Wochenschr 2009; 121: 47-52, doi: 10.1007/s00508-008-1122-2.

17. Wenzhen Y, Kehu Y, Bin M, Yumin L, Quanlin G, Donghai $W$, et al. Moxifloxacin-based triple therapy versus clarithromycin-based triple therapy for first-line treatment of Helicobacter pylori infection: a meta-analysis of randomized controlled trials. Intern Med 2009; 48: 2069-2076, doi: 10.2169/internalmedicine.48.2344

18. Wu C, Chen X, Liu J, Li MY, Zhang ZQ, Wang ZQ. Moxifloxacin-containing triple therapy versus bismuth-containing quadruple therapy for second-line treatment of Helicobacter pylori infection: a meta-analysis. Helicobacter 2011; 16: 131-138, doi: 10.1111/j.1523-5378.2011.00826.x.

19. Kang JM, Kim N, Lee DH, Park YS, Kim YR, Kim JS, et al. Second-line treatment for Helicobacter pylori infection: 10day moxifloxacin-based triple therapy versus 2-week quadruple therapy. Helicobacter 2007; 12: 623-628, doi: 10.1111/ j.1523-5378.2007.00548.x.

20. Zheng XL, Xu L. [Efficacy of second-line treatment based on moxifloxacin triple therapy for Helicobacter pylori infection] Zhonghua Yi Xue Za Zhi 2010; 90: 83-86.

21. Kilic ZM, Koksal AS, Cakal B, Nadir I, Ozin YO, Kuran S, et al. Moxifloxacine plus amoxicillin and ranitidine bismuth citrate or esomeprazole triple therapies for Helicobacter pylori infection. Dig Dis Sci 2008; 53: 3133-3137, doi: 10.1007/s10620-008-0285-z.

22. Della Monica $P$, Lavagna A, Masoero G, Lombardo L, Crocella L, Pera A. Effectiveness of Helicobacter pylori eradication treatments in a primary care setting in Italy. Aliment Pharmacol Ther 2002; 16: 1269-1275, doi: 10.1046/ j.1365-2036.2002.01244.x.

23. Heep M, Kist M, Strobel S, Beck D, Lehn N. Secondary resistance among 554 isolates of Helicobacter pylori after failure of therapy. Eur J Clin Microbiol Infect Dis 2000; 19: 538-541, doi: 10.1007/s100960000288.

24. Wang WH, Wong BC, Mukhopadhyay AK, Berg DE, Cho $\mathrm{CH}$, Lai $\mathrm{KC}$, et al. High prevalence of Helicobacter pylori infection with dual resistance to metronidazole and clarithromycin in Hong Kong. Aliment Pharmacol Ther 2000; 14 901-910, doi: 10.1046/j.1365-2036.2000.00795.x.

25. Chey WD, Wong BC. American College of Gastroenterology 
guideline on the management of Helicobacter pylori infection. $A m$ J Gastroenterol 2007; 102: 1808-1825, doi: 10.1111/j.1572-0241.2007.01393.x.

26. Fischbach W, Malfertheiner P, Hoffmann JC, Bolten W, Bornschein J, Gotze O, et al. S3-guideline "Helicobacter pylori and gastroduodenal ulcer disease" of the German Society for Digestive and Metabolic Diseases (DGVS) in cooperation with the German Society for Hygiene and Microbiology, Society for Pediatric Gastroenterology and Nutrition e. V., German Society for Rheumatology, AWMFregistration No. 021/001. Z Gastroenterol 2009; 47: 12301263, doi: 10.1055/s-0028-1109855.

27. Chang WL, Sheu BS, Cheng HC, Yang YJ, Yang HB, Wu JJ. Resistance to metronidazole, clarithromycin and levofloxacin of Helicobacter pylori before and after clarithromycin-based therapy in Taiwan. J Gastroenterol Hepatol 2009; 24: 1230-1235, doi: 10.1111/j.1440-1746.2009.05829.x.

28. Hung KH, Sheu BS, Chang WL, Wu HM, Liu CC, Wu JJ. Prevalence of primary fluoroquinolone resistance among clinical isolates of Helicobacter pylori at a University Hospital in Southern Taiwan. Helicobacter 2009; 14: 6165, doi: 10.1111/j.1523-5378.2009.00655.x.

29. Zullo A, Perna F, Hassan C, Ricci C, Saracino I, Morini S, et al. Primary antibiotic resistance in Helicobacter pylori strains isolated in northern and central Italy. Aliment Pharmacol Ther 2007; 25: 1429-1434, doi: 10.1111/j.13652036.2007.03331.x.

30. Tankovic J, Lascols C, Sculo Q, Petit JC, Soussy CJ. Single and double mutations in gyrA but not in gyrB are associated with low- and high-level fluoroquinolone resistance in Helicobacter pylori. Antimicrob Agents Chemother 2003; 47: 3942-3944, doi: 10.1128/AAC.47.12.3942-3944.2003.

31. Glocker E, Stueger HP, Kist M. Quinolone resistance in
Helicobacter pylori isolates in Germany. Antimicrob Agents Chemother 2007; 51: 346-349, doi: 10.1128/AAC.00614-06.

32. Chisholm SA, Owen RJ. Frequency and molecular characteristics of ciprofloxacin- and rifampicin-resistant Helicobacter pylori from gastric infections in the UK. J Med Microbiol 2009; 58: 1322-1328, doi: 10.1099/jmm.0.011270-0.

33. Romano M, lovene MR, Russo MI, Rocco A, Salerno R, Cozzolino D, et al. Failure of first-line eradication treatment significantly increases prevalence of antimicrobial-resistant Helicobacter pylori clinical isolates. J Clin Pathol 2008; 61: 1112-1115, doi: 10.1136/jcp.2008.060392.

34. Miyachi $\mathrm{H}$, Miki I, Aoyama $\mathrm{N}$, Shirasaka $\mathrm{D}$, Matsumoto $\mathrm{Y}$, Toyoda M, et al. Primary levofloxacin resistance and gyrA/B mutations among Helicobacter pylori in Japan. Helicobacter 2006; 11: 243-249, doi: 10.1111/j.1523-5378.2006.00415.x.

35. Bago J, Majstorovic K, Belosic-Halle Z, Kucisec N, Bakula V, Tomic M, et al. Antimicrobial resistance of $H$. pylori to the outcome of 10-days vs 7-days moxifloxacin based therapy for the eradication: a randomized controlled trial. Ann Clin Microbiol Antimicrob 2010; 9: 13, doi: 10.1186/1476-0711-9-13.

36. Gisbert JP, Fernández-Bermejo M, Molina-Infante J, PérezGallardo B, Prieto-Bermejo AB, Mateos-Rodríguez JM, et al. First-line triple therapy with levofloxacin for Helicobacter pylori eradication. Aliment Pharmacol Ther 2007; 26: 495500, doi: 10.1111/j.1365-2036.2007.03384.x.

37. Marzio L, Coraggio D, Capodicasa S, Grossi L, Cappello G. Role of the preliminary susceptibility testing for initial and after failed therapy of Helicobacter pylori infection with levofloxacin, amoxicillin, and esomeprazole. Helicobacter 2006; 11: 237-242, doi: 10.1111/j.1523-5378.2006.00407.x.

38. Megraud F. H. pylori antibiotic resistance: prevalence, importance, and advances in testing. Gut 2004; 53: 13741384, doi: 10.1136/gut.2003.022111. 